\title{
Article
}

\section{Attributions of blame in a hypothetical internet solicitation case: Roles of victim naivety, parental neglect and respondent gender}

Rogers, Paul, Wczasek, Ryan and Davies, Michelle

Available at http://clok.uclan.ac.uk/1185/

Rogers, Paul ORCID: 0000-0003-4393-8608, Wczasek, Ryan and Davies, Michelle (2010) Attributions of blame in a hypothetical internet solicitation case: Roles of victim naivety, parental neglect and respondent gender. Journal of Sexual Aggression . p. 1. ISSN 1355-2600

It is advisable to refer to the publisher's version if you intend to cite from the work. http://dx.doi.org/10.1080/13552601003664869

For more information about UCLan's research in this area go to http://www.uclan.ac.uk/researchgroups/ and search for <name of research Group>.

For information about Research generally at UCLan please go to http://www.uclan.ac.uk/research/

All outputs in CLoK are protected by Intellectual Property Rights law, including Copyright law. Copyright, IPR and Moral Rights for the works on this site are retained by the individual authors and/or other copyright owners. Terms and conditions for use of this material are defined in the policies page.

\section{CLoK}

Central Lancashire online Knowledge www.clok.uclan.ac.uk

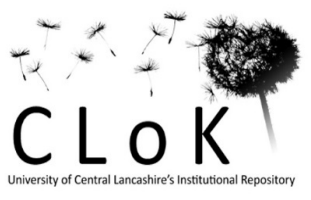


University of Central Lancashire : Research Repository : http://clok.uclan.ac.uk

This is a preprint of an article whose final and definitive form has been published in the Journal of Sexual Aggression, 2010, Taylor \& Francis; Journal of Sexual Aggression is available online at:

http://www.informaworld.com/smpp/content db=all?content=10.1080/13552601003664869

Attributions of blame in a hypothetical internet solicitation case: Roles of victim naivety, parental neglect \& respondent gender

Rogers, P., PhD. Wczasek, R., BSc. \& Davies, M. PhD.

University of Central Lancashire

Preston, UK.

Address for Correspondence:

Dr Paul Rogers

School of Psychology

University of Central Lancashire

Preston PR1 2HE, UK

Tel: +44 (0)1772 894473

Fax: +44 (0)1772 892925

Email: progers@uclan.ac.uk

Keywords: CHILD SEX ABUSE, CYERBERSEXPLOITATION, INTERNET SOLICITATION,

BLAME, NAIVETY, NEGLECT 
Attributions of blame in a hypothetical internet solicitation case: Roles of victim naivety, parental neglect \& respondent gender 


\begin{abstract}
This study investigates attributions towards the perpetrator, victim, and the victim's parents in a hypothetical internet solicitation case. A community sample of 187 respondents read a vignette outlining an internet chat room conversation between a 10 year old girl and a 25 year old man, followed by a depicted sexual assault, before rating 26 attribution items. Principal components analysis extracted six reliable and interpretable factors which were then subjected to a 2 respondent gender $\mathrm{x} 2$ victim age $\mathrm{x} 2$ victim internet naivety $\mathrm{x} 2$ parental neglect between subjects MANOVA. Whilst levels of victim naivety had no impact on any measure, parents who were neglectful of their child's online activities were deemed more culpable for their child's later abuse than were parents who took an active interest in their child's activities. In general, females deemed the victim more credible than males. Implications are discussed.
\end{abstract}




\section{Attributions of blame in a hypothetical internet solicitation case: Roles of victim naivety, parental neglect \& respondent gender}

Academic interest in child sexual abuse (CSA) attributions has increased in recent years (see e.g., Davies \& Rogers 2009). Because negative societal perceptions can damage a child’s long-term recovery from CSA (Broussard \& Wagner, 1988; Fergusson \& Mullen, 1999), studies of CSA attributions may have both theoretical and treatment implications.

In line with the adult rape literature (Pollard, 1992), a fairly robust finding is that men are generally more negative towards child victims of sexual assault than are women (e.g. Back \& Lips, 1998; Bottoms \& Goodman, 1994; Broussard \& Wagner, 1988; Davies \& Rogers, 2004; 2009; Graham, Rogers \& Davies, 2007; Rogers \& Davies, 2007; Rogers, Josey, Davies, 2007). Broussard and Wagner (1988) suggest this is because males tend to confuse encouraging behaviour (from the victim) with sexual consent and as such, attribute a certain degree of responsibility to the victim for their own CSA.

Another consistent finding is that older CSA victims are more negatively evaluated than younger victims. Due to their perceived sexual naivety, younger children also tend to be judged more credible witnesses to their own CSA. Bottoms and Goodman (1994) found that a 6 year old was deemed more credible than a 14 or 22 year old victim of sexual assault and that an 11 year old was deemed more credible than a 14 year old. Similarly, Davies and Rogers (2009) found that a 5 year old CSA victim was deemed more credible than a 10 year old who in turn was deemed more credible than a 15 year old victim.

\section{Cybersexploitation: Internet Grooming \& Solicitation}

Technological advancements in the past decade mean one of the simplest - and due to their anonymity - safest methods for perpetrators to gain sex from children is through the internet (e.g., Craven et al, 2006; Davidson \& Martellozzo, 2008; Dombrowski, LeMasney, \& Ahia, 
2004; Finkelhor, Mitchell \& Wolak, 2004; Fleming, Greentree, Cocotti-Muller, Elias \& Morrison, 2006; Jayawardena \& Broadhurst, 2007, Mitchell, Finkelhor \& Wolak, 2001; 2003; 2005a; b; O’Connell, 2003; O'Connell, Price \& Barrow, 2004; Palmer, \& Stacey, 2004; Wolak, Finkelhor \& Mitchell, 2004). To gain the confidence and trust of potential victims, many CSA perpetrators 'groom’ children before abusing them (Craven, Brown \& Gilchrist, 2006). Under Section 15 of the Sexual Offences Act (2003) sexual grooming occurs when a person aged 18 or over meets intentionally, or travels with the intention of meeting, a child aged under 16 years (whom is not reasonably believed to be over 16 years) in any part of the world, if he/she has met or communicated with that child on at least two earlier occasions, and intends to commit a "relevant offence" against that child either at the time of the meeting or on a subsequent occasion. Further, the intended offence does not have to actually occur with evidence of the perpetrator's intent to offend taken from, for instance, his/her communications with the child before any meeting takes place. Inherent in sexual grooming is an attempt by the perpetrator to befriend a child, gain her/his confidence and trust, lower his/her inhibitions, and ultimately, place the child a position where he/she will acquiesce to abusive activity (Gallup, 2008; Gillespie, 2002).

Online sexual offending against children may also be perpetrated through the more succinct strategy of ‘solicitation' whereby a child is more quickly exposed to unwanted requests for sexual activity and/or sexualised ('dirty’) talk (Mitchell, Finkelhor \& Wolak, 2003). Solicitation occurs when a child is asked to engage in (unwanted) sexual activities and/or sexual talk - including the disclosure of personal sexual information - which (whether wanted or not) is made by an adult. Unlike the legal definition of sexual grooming, which has to have been conducted on at least two occasions by an adult perpetrator, sexual solicitation may only happen on one occasion, and could be perpetrated by another child. Solicitation however, could lead to escalated incidents in which offline contact (e.g. via telephone, mail 
or face-to-face) is attempted (Mitchell et al, 2001; p.3012). Children who are not supervised or who are naïve to the dangers of online contact are particularly prone to such dangers (Gallup, 2008).

The recent European Union (EU) commissioned report “Towards a safer use of the Internet for children in the EU - A parents' perspective" (Gallup, 2008) found that across the 27 member states, three-quarters (75\%) of children aged 6 to 17 years had, in the opinion of at least one parent, used the internet. A similar figure has been cited by the recent " $E U$ Kids Online” report (Livingstone \& Haddon, 2009) which spanned twenty-one EU states, with the most striking rise over the preceding three years being amongst 6-10 year olds (up 60\%). In the UK, between 91-98\% of children are thought to have used the internet either at school and/or at home (Gallup, 2008; Livingstone, 2009).

In another UK study, O’Connell et al (2002) found that a fifth (19\%) of British children aged 9-16 years were regular chat room users of which $40 \%$ claimed to have chatted for long periods with a stranger they had only just 'met' online, with half also claiming to have engaged in at least one sexualised chat room conversation. Likewise, Fleming et al (2006) found that the majority of Australian boys (82.5\%) and girls (62.2\%) aged 13-15 years report being exposed to inappropriate sexualised language whilst online, whilst Mitchell et al (2001; 2003) found that almost a fifth (19\%) of American children aged 10-17 years had experienced at least one episode of online sexual solicitation in the previous year. Finally, a review by the US Research Advisory Board of the Internet Safety Technical Task Force (Schrock \& Boyd, 2009) report that 2\% of New York children aged 9-11 years were asked about their bodies whilst $11 \%$ of those aged $12-14$ years, plus nearly a quarter (23\%) of those aged 15-17 years, were asked sexual questions whilst online. Surprisingly, the same review claims that between 2000 and 2006 the proportion of American youth who received online sexual solicitations fell from $19 \%$ to $13 \%$ with the majority (81\%) of victims aged $14-17$ 
years (Schrock \& Boyd, 2009). Comparatively little is known about how children evaluate websites or how they respond to online contacts they consider problematic or dangerous (Livingstone \& Haddon, 2009).

Schrock and Boyd (2009) argue that because standard definitions of sexual solicitation tend to include a wide range of online activities (such as flirting, innuendo and sexual teasing) where offline meeting is not intended, survey figures often exaggerate the prevalence of 'true' solicitation. That is not to say solicitations are not associated with psychological distress. According to Schrock and Boyd American youth were more at risk to sexual solicitation if they were suffering some forms of psychopathology (e.g. depression, suicidal ideation, self-harming) or engaging in substance abuse. However, as the authors note, these figures may be confounded by greater internet use and thus more frequent talk with strangers. Nevertheless, research suggests that a child's likelihood of experiencing sexual solicitation/harassment is positively associated with their degree of offline sexual and physical abuse (Mitchell, Wolak \& Finkelhor, 2007). Moreover, most parents are (very) worried about online risk to their children (Gallup, 2008; Livingstone \& Haddon, 2009).

A further danger of online interactions between children and adults is if they later meet in person (e.g. Davidson \& Matellozzo, 2008). Thankfully, very few online solicitations actually lead to an offline sexual encounter between adult and child (Schrock \& Boyd, 2009). Yet many children remain ignorant of potential solicitation with only a small minority asking for help following online contact by a stranger (Gallup, 2008). O’Connell et al (2002) found that a tenth of chat room users aged 9-16 years claimed to have met face-to-face someone they had only previously known online, with a small but noticeable percentage claiming their new acquaintance had been nasty and/or abusive towards them. Despite this, approximately a fifth of those sampled were not aware that "people in chat rooms may not be who they say they are”. More recently, Livingstone and colleagues found that around 9\% of EU children (8\% of 
UK children) aged 6-17 years had met online contacts offline (i.e. in person) with the vast majority telling a friend/relative about the intended meeting beforehand (Livingston, 2009; Livingston \& Haddon, 2009). This suggests most children will, nowadays, take steps to minimise the potential risks of internet solicitation. Finally, Wolak et al (2004) found that of 126 internet-initiated sex crimes against American teenagers, 74\% of victims later met their assailant in person, with most subsequently having either oral (18\%) or vaginal/anal penetrative sex (71\%) with him. In 16\% of cases, coercive force was used. Surprisingly, most CSA perpetrators were open about their age and/or desire for sex, at least at the latter stages of online contact with only a fifth (21\%) deliberately disguising their motives (e.g. by offering modelling work). Indeed, the vast majority of perpetrators engaged in sexualised talk (80\%), with sizable numbers having cybersex (20\%) and/or transmitting sexualised photographs (18\%) to their victims. Taken together, these findings suggest children at risk to internet-initiated CSA are generally not naïve about the potential for sexual contact with their on-line acquaintances.

As noted earlier, parental concern for their children’s online safety remains understandably high. Despite their concerns, many parents fail to supervise their child's their online activities (Gallup, 2008; Mitchell et al, 2005a; Schrock \& Boyd, 2009). In the Gallup survey for instance, many EU parents claimed they rarely, if ever, sat with (62\%) or stayed nearby (40\%) their child when he/she was online. Many also claimed they rarely, if ever, discussed their children’s online activities (25\%), checked which sites their children had visited (56\%) or checked their children’s online messages (69\%). Furthermore, a quarter (25\%) placed no restrictions on their children's internet usage with only a small minority spontaneously claiming to have banned their children either from using internet chat rooms (9\%) or from talking online to people they do not know in real life (6\%). These last two figures rose to $61 \%$ and $83 \%$ respectively following direct questioning about which online 
activities their children were not permitted to use. A third (31\%) of EU parents also had no filtering or monitoring software installed on their home computers, with most (64\%) justifying this by stated they "trusted their children on the internet”. Finally, the vast majority of EU parents (88\%) believed the internet would be safer and more effective if schools provided more and better guidance on internet usage. In contrast, Livingstone and Haddon (2009) report that many parents employed range of strategies (e.g., rule-setting, sharing internet usage and/or filtering technologies) to mediate their children's online behaviour, but then acknowledged that little is known about how effective parents are at the reducing risk and/or encouraging resilience in their children.

Having such a degree of trust in the internet and a child's online behaviour may be misguided. Fleming et al (2006) found that Australian teenagers who had been warned about the dangers of internet abuse were less likely to engage in risky online activities (e.g. disclosing their password to an online 'buddy') than those whose parents failed to offer internet safety advice. This type of parental neglect further increases a child's risk to online sexual victimisation.

Previous studies using non-cyber CSA scenarios found that despite being innocent of any actual assault, both (sexually non-offending) parents were attributed a degree of responsibility for their own child's abuse (Waterman \& Foss-Goodman, 1984). Moreover, the younger the child, the more responsibility attributed to parents (Back \& Lips, 1998). As such, it is not unreasonable to expect a certain amount of blame will be attributed to neglectful - but sexually non-offending - parents in a hypothetical case of internet solicitation and subsequent CSA. Interestingly, Livingstone and Haddon (2009) claim many parents seem unaware or unable to mediate their children's online behaviour and should not be relied upon to protect their children against cybersexploitation. Given this, plus the claim that online sexual victimisation has challenged the more 'traditional' view of what constitutes CSA (Davidson 
\& Martellozzo, 2008), there is a growing need to explore negative attributions associated with this problem. To date, only one study - by Davies, Rogers \& Hood (2009) - has done so. Davies and colleagues depicted a hypothetical chat room conversation and subsequent faceto-face meeting between a 15 year old girl and a 40 year old man, where both the perpetrator's age disclosure (honest vs. lies vs. avoidant) and the meeting outcome (consensual vs. non-consensual sex) were experimentally manipulated. In line with previous trends (e.g. Back \& Lips, 1998; Graham et al, 2007; Rogers \& Davies, 2007) men were generally more negative towards victims regardless of perpetrator behaviour or meeting outcome, with women perceiving the eventual CSA to more serious, and the victim less culpable, than their male counterparts. Interestingly, women deemed all outcomes to be reflective of sexual priming (i.e. grooming, solicitation) whereas men were more discerning about what sexual priming entailed. Specifically, men judged the online chat to be more reflective of sexual priming when the perpetrator lied about his real age (claiming to be 22 instead of 40 years old) than when he was honest or when he avoided answering age-related questions. But when the face-to-face meeting ended with non-consensual sex, men were more convinced perpetrator lying was indicative of sexual priming than were women.

One limitation of Davies et al.’s (2009) study is that it fails to assess attributions towards the child's sexually non-offending parents (cf. Back \& Lips, 1998; Waterman \& FossGoodman, 1984). This is an important omission given varying attitudes towards parental monitoring of online activities (Fleming et al, 2006; Gallup, 2008). Nor does it take into account the (female) victim's age or her a priori knowledge of online risks (cf. O’Connell et al, 2002). The current exploratory study aims to rectify these omissions.

\section{$\underline{\text { Study Aims and Overview }}$}


The present study extends the work of Davies et al (2009) by investigating the extent to which respondent gender, victim age, victim naivety (in relation to internet sexual solicitation) and parenting style impact on attributions towards the perpetrator, victim and the victim’s non-offending parents in a hypothetical internet sexual solicitation case.

Respondents are asked to read a short character profile of a female chat room user aged either 10 or 15 years, followed by her initial chat room conversation with an unknown 25 year-old man. As with Davies et al (2009) the latter included the type of behaviour and text shorthand typically found in cases of cybersexploitation, with the perpetrator initiating contact using friendly, non-sexual language before progressing to a more sexualised and flirtatious content (see O'Connell, 2003). The victim was portrayed as responding in a positive manner toward the perpetrator. At first glance, sexually aware behaviours like flirting may seem unrealistic in a child portrayed as young as 10 years. However, a number of developmental psychologists - who view maturity as a multidimensional concept comprising physical, social, psychological emotional and behavioural elements (Peterson, 1996; Coleman \& Hendry, 1990; Galambos \& Tilton-Weaver, 2000; Tilton-Weaver, Vitunski \& Galambos, 2001) - have identified that some children behave in an 'adultoid' fashion. Tilton-Weaver and colleagues claim that adultoids will express a desire to be older than their age and tend to expect certain 'older' privileges such as being allowed to attend mixed gender parties earlier than either mature or immature (i.e. non-adultoid) adolescents. Coleman \& Hendry (1990) suggest adultoids engage in 'adult-like' behaviours (e.g. drinking alcohol, taking drugs) in an attempt to develop and establish their own individual identity. In essence, adultoids are children who appear to be "growing up too fast without really growing up at all” (TiltonWeaver et al, 2001; p.145).

Because of their pseudo-mature thinking and behaviour patterns adultoids may be at particular risk of sexual abuse. Indeed, Ybarra, Leaf and Diener-Westl (2004) showed that 
children who partake in adult-like behaviours (e.g., unsupervised internet use) and who are then targeted by online sexual abusers, are more likely to show severe depressive symptoms than those who do not undertake such activities. Considering these potentially serious consequences, both the 10 and 15 year old victims in the present study were portrayed as being of an adultoid type. The scenario concluded by described how the two characters met for lunch after which the girl claims she was forced into having full penetrative sex.

Several hypotheses are forwarded. First, male respondents will be more negative towards the victim, and more positive towards the perpetrator (regardless of condition) than will females. Second, a 10 year old cybersexploitation victim will receive less negative attributions generally than a 15 year old victim. Third, the perpetrator of CSA on a 10 year old will be more negatively evaluated than those who abuse a 15 year old victim. Similarly, the (sexually non-offending) parents of the younger child will be more negatively evaluated than parents of her older counterpart. Fifth, more negativity will be attributed to a victim already educated about the dangers of chat room abuse than a victim who has not been educated in such matters. Finally, sexually non-offending but neglectful parents will be more negatively evaluated than caring parents who take an active interest in their child's online activities.

\section{Method}

\section{Design}

The study employed a 2 respondent gender (male vs. female) x 2 victim age (10 years vs. 15 years) x 2 victim internet education (educated vs. uneducated) x 2 parental style (neglectful vs. caring) between subjects design. Dependent variables included attributions of victim/perpetrator/parental blame, victim credibility and perceived assault severity Respondents were randomly allocated to each condition. 


\section{Respondents}

A total of 250 questionnaires were distributed of which 190 usable questionnaires were returned; a response rate of $76.0 .0 \%$. The sample comprised 89 males plus 96 females (5 missing gender data) with an age range of $18-84$ years ( $M=41.3$ years, $S D=14.8$ years). The vast majority of respondents were Caucasian (97.8\%), British (98.9\%) and in full-time employment (74.4\%), although a sizeable number of both students (7.9\%) and retired (8.9\%) were also included. Around two-thirds (62.8\%) of the sample were either married, engaged or co-habiting with just under half (41.3\%) being parents with an average (modal) of two children each.

\section{Materials}

A questionnaire booklet, adapted from Davies et al (2009), was created for the present study. This contained standardised instructions (including details about confidentiality, anonymity and informed consent) plus the following:

Scenario: A hypothetical scenario depicted a 10 or 15 year old girl ('Sarah’) engaging in an online chat room conversation with a 25 year old man ('Robert') whom she had never met before. Sarah was described as a regular user of chat rooms with her parents described as either interested in her online activities (i.e. caring) or too busy watching TV to pay attention (i.e. neglectful). Details of whether Sarah had received internet safety lessons at school were also provided (for a discussion of current internet safety education policy, see Davidson \& Martellozzo, 2008). A transcript of Sarah and Robert's chat room conversation was also included in which, after initial pleasantries the language becomes increasingly sexualised (cf. O’Connell, 2003) with eventually the two characters arranging to meet for lunch. Thus, technically, the offence was depicted as internet solicitation (which requires just one cyberinteraction) rather than internet grooming (which required as least two; Sexual Offences Act, 2003). The final section of the scenario described Sarah's account of how, two days later, she 
met Robert, went back to his house, was (allegedly) forced into having full, penetrative sex with him against her will and how subsequently, she was upset and distressed by these events (see Appendix A).

Attributions: Twenty-six attribution items, adapted from previous work by Davies et al (2009), assessed perceptions of perpetrator, victim and parental blame (e.g. 'Sarah’s family could have stopped Sarah from talking to Robert on the internet'), victim credibility (e.g. ‘Typical children of Sarah’s age can be trusted to tell the truth’) and assault severity (e.g. 'Sarah's life will be negatively affected by the events'). All items were rated on a 7 point Likert scale from 1 'strongly disagree' to 7 'strongly agree' and were presented in the same order regardless of condition.

Demographics and Personal Experiences Questionnaire: A personal demographics questionnaire assessed respondent gender, age, current relationship status, occupation status, ethnicity and nationality. Nine personal experience items also assessed respondents’ ownership of a computer (yes/no), frequency of chat room use (measured on a 5 point scale from 'daily' to 'never’), whether they had ever met in person someone they had previously only 'known' online (yes/no), whether they had experienced any kind of sexual assault either before or after the age of 16 years (both yes/no), the number and if applicable age(s) of their children, the frequency of their children's chat room use (again, from 'daily' to 'never') and finally, whether to their knowledge any of their children had experienced any kind of sexual abuse (yes/no).

Finally, a detachable debriefing sheet detailing contact details of one experimenter (RW) and several victim support organisations was also provided.

\section{Procedure}


Questionnaires were distributed via door-to-door 'cold calling' of a convenience sample of homes - randomly selected via local A-to-Z maps (cf. Graham et al, 2007) - in three cities in the North-West (Preston) and Midlands (Nottingham, Stoke-on-Trent) regions of England. Sampling was not stratified in any way other than to ensure questionnaires were handed only to adult residents who, because CSA is a sensitive topic, were given a brief verbal introduction to the study and asked in person if they would like to participate. Those who did were then asked to complete the questionnaire independently within a 24 hour period after which questionnaires would be collected by the same experimenter (RW) who distributed them. This 24 hour 'cooling-off' period allowed participants additional time to reflect and ensure they were comfortable with the subject matter (all were). Experimenter contact details were supplied on the questionnaire so participants could ask further questions and/or return completed questionnaires via the post if this was preferable. Only one questionnaire booklet was handed to an adult within each household with standardised instructions informing participants to read the scenario carefully, complete the questions as honestly as possible and not to confer with anyone. Participation was entirely voluntary with complete anonymity assured throughout. No form of payment made. All aspects of the study conformed to School of Psychology and British Psychological Society (BPS) ethical guidelines.

\section{Results}

\section{Respondents’ Personal Experiences}

Whilst three-quarters (75.5\%) of the final sample owned a home computer, most respondents (83.4\%) claimed they never used internet chat rooms, with just under a tenth (8.3\%) using them very often or daily. Of those that did use chat rooms, a quarter (23.3\%) said they had later met face-to-face someone they had previously only 'known' online. 
A sizeable proportion of the sample claimed to have been victim of sexual assault either before $(12.2 \%)$ or after $(6.1 \%)$ the age of 16 years. Neither group were associated with more (or less) frequent chat room use or post chat room meetings.

Finally, half (46.0\%) of all parents claimed their children had used internet chat rooms at least once, with a fifth (18.4\%) claiming their children were regular or daily users. A tenth (10.4\%) of all parents also reported that at least one of their children had been sexually assaulted although, again, this was unrelated to the frequency of (their children's) internet chat room use.

\section{Principal Components Analysis}

All attribution DVs were (re)coded so that high scores represented a pro-victim/antiperpetrator/anti-parent stance. A principal components analysis (PCA) with varimax rotation was then performed on the (re)coded DVs. PCA extracted 8 usable factors which explained $66.8 \%$ of total variance as illustrated in Table 1.

Insert Table 1 about here

As Table 1 shows, 4 items (perpetrator blame, perpetrator grooming, perpetrator manipulate and perpetrator responsibility) loaded onto Factor 1 which had high internal reliability (alpha $=.85$ ) and so was interpreted as 'perpetrator culpability’. Four items (victim truthfulness, victim age truthfulness, victim age competence, and victim age lie/naivety) also loaded onto Factor 2. Factor 2 had an acceptable level of internal reliability (alpha $=.72$ ) and was subsequently named ‘victim credibility’. Likewise, 4 items (family blame, family responsibility, family guilt and family prevention) loaded onto Factor 3. This had high internal reliability (alpha $=.80$ ) and was thus named 'parent culpability'. A further 3 items (assault severity, police treatment and victim trauma) loaded onto Factor 4 which had high 
internal reliability (alpha $=.83$ ) and was interpreted as 'assault severity'. Three items (victim blame, victim could have prevented assault and victim sympathy) loaded onto Factor 5 where internal reliability was again acceptable (alpha $=.71)$. Factor 5 was subsequently interpreted as 'assault unavoidability'. Two items (victim trust and victim naivety) loaded onto Factor 6. This too had high internal reliability (alpha $=.77$ ) and was labelled 'victim naivety'. Another two items (victim responsibility and victim guilt) had moderate, but acceptable, internal reliability (alpha $=.67$ ) with this factor - Factor 7 - named 'victim culpability'. Finally, two items (perpetrator guilt and family could have stopped online chat) loaded on to Factor 8, which, because of very poor internal reliability (alpha =-.26), was removed from further analysis. Two other singlets were also removed. The 7 remaining factors were computed.

\section{Preliminary Data Screening}

Boxplot analysis suggested three extremities ought to be removed, leaving a final sample size of 187. Tests for normality revealed that six of the seven factors were skewed (all $K-S$ statistics from 1.54 to 3.32; all $p$ 's <.05) - the single exception being 'parent culpability' ( $K$ $S=1.28 ; p=.077)$ - with tests for the homogeneity of covariance not confirmed $(p<.001)$. A wealth of CSA blame studies have employed (multivariate) analysis of variance despite likely violations in assumptions of normality and/or homogeneity of (co)variance (e.g. Back \& Lips, 1998; Bornstein, Kaplan \& Perry, 2007; Davies et al., 2009; Maynard \& Wiederman, 1997; Waterman \& Foss-Goodman, 1984). Thus, because of the general robustness of (M)ANOVA (Tabachnik \& Fidell, 2007), coupled with its widespread use in studies of this ilk, MANOVA was also deemed appropriate for current/comparative purposes (see also Keselman, Huberty, Lix, Olejnik \& Cribbie et al., 1998; Yu, 2009). No evidence of factor multicollinearity was found. 


\section{Multivariate Analysis of Variance (MANOVA)}

A 2 respondent gender $\mathrm{x} 2$ victim age $\mathrm{x} 2$ victim internet education $\mathrm{x} 2$ parental interest between subjects MANOVA was performed across the seven retained factors. Means and standard deviations are reported in Table 2.

Insert Table 2 about here

Results revealed two significant multivariate effects across composite factor scores. The first was for family neglect (Wilks Lambda $=.85 ; F(7,159)=4.11 ; p<.001 ;$ eta $^{2}=.15$ ) with respondents making more pro-victim/anti-perpetrator/anti-family judgements given neglectful parents than they did for interested parents. The second multivariate effect was for respondent gender (Wilks Lambda $=.91 ; F(7,159)=2.17 ; p=.040 ;$ eta $\left.^{2}=.09\right)$ with females generally more pro-victim/anti-perpetrator/anti-family than men. No other significant multivariate main or interaction effects were found.

Subsequent post-hoc univariate ANOVA revealed several significant effects. First, a significant respondent gender effect was found for victim credibility ratings $(F(1,165)=4.52$; $p=.035 ;$ et $a^{2}=.03$ ), with females judging the victim more credible than males. Second, parental style manipulations had a significant effect on judgements of parent culpability $\left(F(1,165)=20.98 ; p<.001 ; e t a^{2}=.11\right)$, with neglectful parents deemed more culpable than caring parents. Third, parental style also had a significant effect on victim naivety scores $\left(F(1,165)=4.52 ; p=.035 ; e^{2} a^{2}=.03\right)$, with the victim deemed less naïve (generally) if her parents neglected rather than cared about her online activities. Finally, a significant three-way parental style $\mathrm{x}$ victim age $\mathrm{x}$ respondent gender interaction effect was found across victim naivety scores $\left(F(1,165)=4.84 ; p=.029 ;\right.$ eta $\left.^{2}=.03\right)$. Inspection of $95 \%$ confidence interval (CI) graphs revealed that males rated the 15 year old/cared for victim to be less naïve than the other three categories of victim, with females rating the10 year old/neglected victim to be 
more naïve than the rest. Post-hoc simple effects analyses via independent samples t-tests (with alpha adjusted to .005) failed to confirm these differences

\section{Additional Findings}

The effects of respondents' individual demographic and personal experiences on factor scores were also tested via a series of either correlation analyses or one-way MANOVA. Only parent culpability ratings correlated with respondent age ( $r=-.16 ; p=.043$; $n=171$; $t$ wotailed), with older respondents rating the victim's parents less culpable for their daughter's CSA. Interestingly, a significant difference in victim credibility ratings was found across respondents' parental status $\left(F(1,173)=4.49 ; p=.035\right.$; eta $\left.^{2}=.03\right)$ with parents $(M=5.12$; $S D=1.00)$ judging the victim more credible than non-parents $(M=4.80 ; S D=.94)$. Finally, parental culpability ratings were positively correlated with how often respondents’ own children used internet chat rooms ( $r h o=.28 ; p=.009 ; n=85$; two-tailed); those whose children were frequent chat room users were more blaming of the victim's parents in the depicted scenario. No other differences were found across respondent demographics and personal experience items.

\section{Discussion}

Overall, respondents did not make negative attributions towards the victim, and deemed the perpetrator to be generally culpable for assaulting the girl. Respondents were moderately critical of the victim's (sexually non-offending) parents, supporting previous claims that parents who do not protect their children from internet grooming (and later CSA) are deemed at least partially accountable for their child’s abuse (cf. Back \& Lips, 1998; Graham et al, 2006; Waterman \& Foss-Goodman, 1984). Significant findings will now be discussed in detail. 
The perpetrator was deemed equally culpable by men and women, regardless of manipulations in victim age, victim education and/or parental interest in the child's online activities. Previous studies have found mixed evidence for respondent gender differences on this type of measure (e.g. Davies \& Rogers, 2004; 2007; Graham et al, 2006; Rogers \& Davies, 2007) so the lack of difference reported here is perhaps not surprising. However, respondent gender differences were revealed in attributions towards the victim. In line with predictions, men deemed the victim less credible than did women. These data mirror respondent gender differences found in other CSA contexts (e.g. Davies \& Rogers, 2009; Rogers \& Davies, 2007) and imply men are also less trusting of cybersexploitation as well as other, more 'traditional' CSA testimonies. Because the majority of internet perpetrators are male (e.g., Mitchell et al, 2003; 2005b) it is plausible men were more able to identify with the perpetrator and as such, were more inclined to making defensive attributions in his favour (cf. Shaver, 1970). In the present context, this was achieved by undermining the credibility of his victim's account. As a means of testing this defensive attributions interpretation further, it would be interesting to see whether similar trends emerge for cybersexploitation against a young male victim by a female internet perpetrator (cf. Rogers \& Davies, 2007).

Surprisingly, the current cybersexploitation victim was deemed just as credible regardless of her age. The lack of victim age differences reported here is contrary to most other CSA attribution studies (e.g. Bottoms \& Goodman, 1994) including those which compare a 10 versus a 15 year old victim (Davies \& Rogers, 2009). In the current depiction, the child (regardless of age), responded positively to the perpetrator's solicitation and suggested meeting. That is, she displayed signs of adultoid behaviour (e.g., Tilton-Weaver et al, 2001). Thus, respondents may have viewed the girl as behaving inappropriately old for her age (regardless of what age this was) even though she later clearly did not consent to sexual intercourse. This is worrying and has implications for how real-life CSA victims might be 
perceived. A considerable number of children do behave in an adultoid manner (especially when on-line) and such behaviour could increase their vulnerability to sexual solicitation and exploitation (e.g., Mitchell et al, 2001). More research is needed to explore this issue further.

The victim was also deemed equally credible regardless of whether or not she had been forewarned about internet chat rooms by her parents and/or received internet safety education from her school. In short, receiving both informal and formal teaching on the risks of cybersexploitation had little impact on the victim's perceived ability to give competent and/or honest testimony about it.

As predicted, sexually non-offending parents who neglected their daughter's online activities were deemed more culpable than those who forewarned her about the potential dangers of internet grooming. These data are consistent with previous studies using other CSA depictions (Back \& Lips, 1998; Waterman \& Foss-Goodman, 1984). For instance, Waterman and Foss-Goodman (1984) found that a major reason given by respondents who blamed non-offending parents for their own child's abuse was that they [parents] "shouldn't have left their child alone” (p.341). It seems that parents’ protective function now extends to them monitoring who their children chat online with and thus to not "leaving their child alone” in cyberspace. As such one may treat current findings as a modern, technological update of earlier CSA attributions.

Surprisingly, the victim’s sexually non-offending parents were deemed equally culpable by men and women, regardless of whether the girl was aged 10 or 15 years, and/or if she had received internet safety education from school. These unexpected findings contradict previous claims relating to parental blame (Waterman \& Foss-Goodman, 1984) especially those relating to CSA against a younger child (Back \& Lips, 1998; Rogers et al, 2007). First, it seems men and women are equally blaming of parents who allow their own child to use internet chat rooms. Second, it seems such blame extends to both teenage and pre-teenage 
children. Finally, men and women are equally likely to assume that responsibility for ensuring children receive (formal) internet safety training falls squarely on the shoulders of that child's educational establishment. Given evidence of parents’ concern over their children’s online behaviour (e.g. Gallup, 2008; Livingstone \& Haddon, 2009), these findings warrant further investigation.

Interestingly, the victim was deemed less naive when her parents were neglectful than when they had previously warned her about the dangers of internet chat rooms. This was regardless of the girl's age. The implication here is that respondents believed any child who chats online with, and then meets, someone she does not already know is more gullible precisely because she is aware of - but chooses to ignore - the potential risks involved. Thus, victim naivety in this sense seems to reflect the child's dismissive response to parental advice. With this in mind, the lack of a significant effect across neglectful versus caring parents in victim culpability scores is particularly interesting as it suggests respondents had differing views about a child's naivety (innocence) versus blameworthiness. Whilst the dismissive child was judged more naive because of her rejection of parental care, she was not simultaneously blamed for her own CSA having reacted this way. Future studies need to explore these attributions further. The notion that victim naivety reflected the child's unwillingness to heed (parental) advice may also explain why naivety ratings failed to differ across victims who received versus had no internet safety education at school. It seems naivety in the present context represents the child's dismissive response to all counsel from their elders.

\section{$\underline{\text { Additional Findings }}$}

Attributions did not differ across the majority of respondents' demographic and personal history characteristics and to that end, the sample was treated as a largely homogenous and 
representative group. The finding that older respondents and those with children who used internet chat room both attributed more blame to the girl's sexually non-offending parents presumably reflects these respondents’ greater maturity and experience with life/children. A similar interpretation may also explain why respondents who are themselves parents judged the victim more credible than those who are childless. Finally, the lack of blame attribution differences across respondents who have versus have not experienced sexual assault themselves is consistent with the majority of studies employing more traditional CSA vignettes (e.g. Graham et al, 2007).

\section{Summary, Methodological Issues \& Future Research}

The present exploratory study is only the second to examine attributions in a hypothetical cybersexploitation case and as such, represents a valuable contribution to existing literature. The use of hypothetical cybersexploitation/CSA scenarios is a good way of investigating peoples' perceptions whilst overcoming the obvious practical and ethical limitations associated with real-world cases. To that end, hypothetical studies can also make and important contribution to social research and educational/public awareness programmes (Davies \& Rogers, 2004; see also Schoenberg \& Ravdal, 2000; Sleed, Durrheim, Kriel, Solomon \& Baxter, 2002; West, 1982). By incorporating a mock, but realistic, chat room transcript, the current study is, arguably, more ecologically valid than previous studies of this kind. Whilst some respondents may find cyber-text a little difficult to comprehend (at least at first), we feel the benefits of such methods outweigh the potential costs, especially as a glossary is included.

The current study is, of course, not without its limitations. First, it depicts a somewhat 'speedier' episode of internet solicitation rather than internet grooming (cf. Sexual Offences Act, 2003) which may appear to some a less likely/realistic scenario which might, in turn, 
impact on CSA attributions. For example, by agreeing to meet up so soon after cyber contact had been initiated respondents may have been primed to believe the child victim in the present context was (sexually) 'easy'. But some sexual assaults may occur against children who previously have had only brief online correspondence with, and who have quickly begun to trust a seemingly friendly, older person. Thus, the situation depicted here is not totally unrealistic. Nevertheless, future studies should also investigate attributions towards situations that involve cyber-relationships that have taken longer to develop and where the perpetrator has entrusted, and subtly manipulated, his (or her) victim through online grooming (cf. Gallup, 2008; Gillespie, 2002; Livingstone \& Haddon, 2009).

Secondly, the scenario depicted sexually non-offending (caring) parents who have forewarned their daughter about the dangers of speaking to strangers online. Given that parental reactions to a child's online activity varies considerably (Gallup, 2008; Livingstone \& Haddon, 2009), future research should investigate online sexual abuse across a range of different contexts.

Thirdly, findings from the present study are restricted to just 10 and 15 year old victims. It would be interesting to see how members of the general public make attributions following the online sexual solicitation or grooming of children much younger than this, especially given differing levels of school education and/or parental interest depending on victim age.

Fourth, the use of 'cold calling' convenience sampling within three UK cities (Preston in the North-West of England, plus Nottingham and Stoke-on-Trent in the Midlands) may limit the generalizability of current findings. Future (trans) national replications seem warranted.

Finally, despite a comparatively high response rate, individual differences in the characteristics of non-responders (cf. Korkeila, Suominen, Ahvenainen, Ojanlatva, ARautava, Helenius \& Koskenvuo, 2001) may also bias current findings. For instance, those with personal experiences of cybersexploitation and/or other forms of (child sexual) abuse may 
have refused to participate in this study because they found current test materials too distressing, again limiting the generalizability of reported trends. That said current and past evidence CSA blame attributions do not differ across adults with versus without personal histories of CSA (Graham et al, 2007) suggest potential response biases will have a limited impact on trends reported here.

\section{$\underline{\text { General Conclusion }}$}

In conclusion, current findings suggest that the level of interest (sexually non-offending) parents have their children's online activities is particularly important in cases of cybersexploitation. Raising public awareness of internet safety (cf. Davidson \& Martellozzo, 2008; Gallup, 2008), and more generally of damaging CSA myths (e.g., Collings, 1997) are important goals in helping to reduce the prevalence of (internet-initiated) CSA and in championing the fair treatment of CSA survivors. Whilst internet grooming is just one aspect of the current CSA 'epidemic’ (cf. Fergusson \& Mullen, 1999), the speed of recent technological advancements means it remains an increasingly common problem. Studies like the present one must continue apace so that factors impacting on lay beliefs surrounding cybersexploitation can be more readily understood and challenged. 


\section{Acknowledgments}

The authors would like to thank several anonymous reviewers for their comments on an earlier draft of this paper.

\section{References}

Back, S. \& Lips, H. (1998). Child sexual abuse: Victim age, victim gender and observer gender as factors contributing to attributions of responsibility. Child Abuse \& Neglect, 22(12), 1239-1252.

Bornstein, B. H., Kaplan, D. L., \& Perry, A. R. (2007). Child abuse in the eyes of the beholder: Lay perceptions of child sexual and physical abuse. Child Abuse \& Neglect, 31, 375-391.

Bottoms, B., L. \& Goodman, G., S. (1994). Perceptions of children's credibility in sexual assault cases. Journal of Applied Social Psychology, 24(8), 702-732.

Broussard, S., D. \& Wagner, W., G. (1988). Child sexual abuse: Who is to blame? Child Abuse \& Neglect, 12, 563-569.

Coleman, J. C. \& Hendry, L. (1990). The nature of adolescence (2nd edition). Florence, KY: Taylor \& Frances/Routledge

Collings, S., J. (1997). Development, reliability and validity of the child sexual abuse myth scale. Journal of Interpersonal Violence, 12(5), 656-674.

Craven, S., Brown, S. \& Gilchrist, E. (2006).Sexual grooming of children: Review of literature and theoretical considerations. Journal of Sexual Aggression, 12(3), 287-299.

Craven, S., Brown, S. \& Gilchrist, E. (2007). Current responses to sexual grooming: Implication for prevention. The Howard Journal 46(1), Feb 2007, 60-71.

Davidson, J., \& Martellozzo, E. (2008). Protecting children online: Towards a safer 
internet. In G. Letherby, K. Williams, P. Birch, \& M. Cain (eds.). Sex as Crime? (pp. 338355). Collompton, Devon: Willan

Davies, M. \& Rogers, P. (2004). Attributions towards victims and perpetrators in a child sexual abuse case: Roles of respondent, perpetrator, and victim gender. Forensic Update A Publication of the Forensic Division of British Psychological Society, 79, Oct 2004, 17 23.

Davies, M. \& Rogers, P. (2009). Perceptions of blame and credibility toward victims of childhood sexual abuse: Differences across victim age, victim-perpetrator relationship and respondent gender in a depicted case. Child Sexual Abuse, 18(1), 78-92

Davies, M., Rogers, P., \& Hood, P. (2009). Perceptions of Child Sexual Abuse in a Hypothetical Cybersexploitation Case. Journal of Child Sexual Abuse, 18(4), 422-441.

Dombrowski, S., LeMasney, J. W. \& Ahia, C. E. (2004). Protecting children from online sexual predators: Technological, psychoeducational, and legal considerations. Professional Psychology: Research \& Practice, 35(1), 65-73.

Fergusson, D., M. \& Mullen, P., E. (1999). Childhood sexual abuse: An evidence based perspective. Thousand Oaks, CA, Sage.

Fleming, M., J., Greentree, S., Cocotti-Muller, D., Elias, K., A. \& Morrison, S. (2006). Safety in cyberspace: Adolescents’ safety an exposure online. Youth \& Society, 38(2), 135-142.

Finkelhor D, Mitchell K.J, Wolak J. (2004). Online victimization: A report on the nation's youth. 2000. http://www.missingkids.com/en_US/publications/NC62.pdf. Accessed 25th March 2009

Galambos, N. L. \& Tilton-Weaver, L. C, (2000). Adolescents’ psychosocial maturity, problem behaviour and subjective age: In search of the adultoid. Applied Developmental Science, 4(4), 178-192.

Gallup (2008). Towards a safer use of the internet for children in the EU - a parents' 
perspective. [online] Available via http://ec.europa.eu/information_society/activities/sip/ docs/eurobarometer/analyticalreport_2008.pdf. Accessed 22 March 2009

Gillespie, A. (2002). Child protection on the internet - challenges for criminal law. Child \& Family Law Quarterly, 14, 411-425.

Graham, L., Rogers, P. \& Davies, M. (2007). Attributions in a hypothetical child sexual abuse case: roles of abuse type, family response and respondent gender. Journal of Family Violence, 22(8), 733-745.

Jayawardena, K. P. \& Broadhurst, R. (2007) Online child sex solicitation: Exploring the feasibility of a research ‘sting’. International Journal of Cyber Criminology 1(2), 228-248.

Keselman, H. J., Huberty, C., Lix, L. M., Olejnik, S., Cribbie, R. A., Donahue, B., Kowalchuk, R. K., Lowman, L. L., Petoskey, M. D., \& Keselman, J. C. (1998). Statistical practices of educational researchers: An analysis of their ANOVA, MANOVA, and ANCOVA analyses. Review of Educational Research, 68, 350-386.

Korkeila, K., Suominen, S. Ahvenainen, J., Ojanlatva, A. Rautava, P., Helenius, H. \& Koskenvuo, M. (2001). Non-response and related factors in a nation-wide health survey. European Journal of Epidemiology, 17(11), 991-999.

Livingstone, S. (2009). UK children go online: End of Award Report. London: EU Kids Online Network/London School of Economics [online]. http://www.lse.ac.uk/collections/children-go-online/. Accessed 02/07/09 Livingstone, S. \& Haddon, L. (2009) EU Kids Online: Final Report. London: EU Kids Online Network/London School of Economics and Political Science [online]. http://www.lse.ac.uk/collections/EUKidsOnline/Reports/EUKidsOnlineFinalReport.pdf. Accessed 02/07/09.

Maynard, C. \& Wiederman, M. (1997). Undergraduate students’ perceptions of child sexual 
abuse: Effects of age, sex and gender-role attitudes. Child Abuse \& Neglect, 21(9), 833844.

Mitchell, K., J. Finkelhor, D. \& Wolak, J. (2001). Risk factors for and impact of online sexual solicitation of youth. Journal of the American Medical Association 285(23), June 2001, 3011-3014.

Mitchell, K., J. Finkelhor, D. \& Wolak, J. (2003). Victimization of youths on the internet. Journal of Aggression, Maltreatment \& Trauma, 8(1-2), 1-39.

Mitchell, K., J. Finkelhor, D. \& Wolak, J. (2005a). Protecting youth online: Family use of filtering and blocking software, Child Abuse \& Neglect, 29(7), 753-765.

Mitchell, K., J. Finkelhor, D. \& Wolak, J. (2005b). The internet and family and acquaintance sexual abuse. Child Maltreatment, 10(1), February 2005, 49-60.

Mitchell, K. J., Wolak, J \& Finkelhor, D. (2007). Youth internet users at risk for the most serious online sexual solicitations. American Journal of Preventative Medicine 32(6), $532-537$.

O'Connell, R. (2003). A typology of cybersexploitation and online grooming practices. University of Central Lancashire Cyberspace Research Unit [online]. http://www.uclan.ac.uk/old/host/cru/docs/cru010.pdf. Accessed 24 April 2008.

O’Connell, R., Sange, S., Barrow, C (2002). Young people's use of chat rooms: Implications for policy strategies and programs of education. Report for Sub-group F Home Office Internet Task Force, Cyberspace Research Unit, University of Central Lancashire, Preston, UK.

O'Connell, R., Price, J., \& Barrow, C. (2004). Cyber stalking, abusive cybersex and online grooming: A programme of education for teenagers. University of Central Lancashire Cyberspace Research Unit [online]. http://www.uclan.ac.uk/old/host/cru/docs/NewCyberStalking.pdf. Accessed 24/04/2008 
Palmer, T., \& Stacey, L. (2004). Just one click - Sexual abuse of children and young people through the internet and mobile phone technology. Barnardo's: Ilford, Essex

Peterson, C. (1996). Looking forward through the lifespan; Developmental Psychology (3rd edition.). Englewood Cliffs, NJ: Prentice-Hall

Pollard, P. (1992). Judgements about victims and attackers in depicted rapes: A review. British Journal of Social Psychology, 31, 307-326.

Rogers, P. \& Davies, M. (2007). Perceptions of credibility and attributions of blame towards victim in a childhood sexual abuse case: Gender and age factors. Journal of Interpersonal Violence, 22(5), 566-584.

Rogers, P., Josey, N. \& Davies, M. (2007). Victim age, attractiveness and abuse history as factors in the perception of a hypothetical child sexual abuse case. Journal of Sexual Aggression, 13(2), 121-137.

Schoenberg, N., E. \& Ravdal, H. (2000). Using vignettes in awareness and attitudinal research. International Journal of Social Research Methodology, 3(1), 63-74.

Schrock, S. \& Boyd, D. (2009). Online threats to youth: Solicitation, harassment, and problematic content: A review by the Research Advisory Board of the Internet Safety Technical Task Force [on-line]. Available via http://cyber.law.harvard.edu/research/isttf/RAB. Accessed 16/06/2009

Sexual Offences Act (2003). [on-line]. Available via http://www.sentencing-guidelines. gov.uk/docs/82083-COI-SCG_final.pdf. Accessed 22 March 2009

Shaver, K.,G. (1970). Defensive attribution: Effects of severity and relevance on the responsibility assigned for an accident. Journal of Personality \& Social Psychology, 14, 101-113.

Sleed, M., Durrheim, K., Kriel, A., Solomon, V. \& Baxter, V. (2002). The effectiveness of 
the vignette methodology: A comparison of written and video vignettes in eliciting responses about date rape. South African Journal of Psychology, 32(3), 21-28.

Tabachnick, B. G. \& Fidell, L., S (2007). Using Multivariate Statistics (5th edition.). Boston: Allyn \& Bacon.

Tilton-Weaver, L. C, Vitunski, E. T., Galambos, N. L. (2001). Five images of maturity in adolescence: What does 'grown up’ mean? Journal of Adolescence, 24(2), 143-158.

Waterman, C., K. \& Foss-Goodman, D. (1984). Child molesting: Variables relating to attribution of fault to victims, offenders and non-participating parents. Journal of Sex Research, 20(4), 329-349.

West, P. (1982). Reproducing naturally occurring stories: Vignettes in survey research. Working Paper May 1982; MRC Social \& Public Health Sciences Unit, Aberdeen.

Wolak, J., D. Finkelhor, D. \& Mitchell, K. (2004). Internet-initiated sex crimes against minors: Implications for prevention based on findings from a national study. Journal of Adolescent Health, 35(5), 424.e11-424.e20.

Ybarra, M.L., Leaf, P.J. \& Diener-West, M (2004). Sex differences in youth-reported depressive symptomatology and unwanted internet sexual solicitation. Journal of Medical Internet Research, 6(1), e5. [on-line] via http://www.pubmedcentral.nih.gov/articlerender.fcgi?artid=1550591. Accessed 25th March 2009.

Yu, C-H. (2009). Parametric tests: Restrictions of parametric tests [on-line] available at http://www.creative-wisdom.com/teaching/WBI/parametric_test.shtml. (Accessed 24/11/2009). 


\section{Appendix A: Internet Grooming Scenario}

\section{Please read the following description carefully:}

Sarah is a happy and outgoing 10 year [15 year] old girl whose favourite pastime is using the internet; she particularly enjoys speaking to people in online chat rooms.

Her parents take a great interest in Sarah's schoolwork and general activities. Whilst they do not mind her using internet chat-rooms they have often warned her about the danger of speaking to people that she does not know. [Her parents let her do what she likes on the computer as they are usually too busy watching television to pay attention to her activities]. As part of her information technology classes at school, Sarah had a lesson specifically on internet safety and the dangers of using chat-rooms. Sarah enjoyed this class and achieved a Grade A for her coursework. [Sarah does not receive information technology lessons at school].

One evening, Sarah is online and a 25 year old man named Robert invites her to a private chat room, they have a conversation which goes as follows:

\section{Guide to Internet Abbreviations:}

$$
\begin{array}{ll}
\text { asl } & \text { - age/sex/location (normally the first thing people ask each other in chat rooms) } \\
\text { lol } & \text { - laugh out loud (used to denote a “joking” tone to the phrase just written) } \\
\mathrm{m} & \text { - male } \\
\mathrm{f} & \text { - female } \\
\mathrm{b} 4 & \text { - before } \\
4 & \text { - for } \\
2 & \text { - to/too } \\
\text { wk } & \text { - week } \\
\text { u } & \text { - you } \\
\text { wot } & \text { - what } \\
\text { r } & \text { - are } \\
\text { pic } & \text { - picture } \\
\text { plz } & \text { - please } \\
\text { Yr } & \text { - your/you're } \\
\text { yrself } & \text { - yourself } \\
\text { tho } & \text { - though } \\
\text { bf } & \text { - boyfriend } \\
\text { addy } & \text { - address } \\
\text { c } & \text { - see } \\
\text { eva } & \text { - ever } \\
\text { perv } & \text { - pervert } \\
\text { b } & \text { - be } \\
\text { wiv } & \text { - with }
\end{array}
$$

Robert: hi asl?

Sarah: 10/f/uk

Robert: I'm probably 2 old 4 u then lol

Sarah: asl plz?

Robert: 25/m/uk - bit old 4 u!!

Sarah: OK

Robert: good! I'm in Lancs near Prestley, where $\mathrm{r} u$ ?

Sarah: I'm in Prestley 2, small world lol wots yr name?

Robert: robert, boring! Yrs?

Sarah: sarah

Robert: wot u like 2 do for fun?

Sarah: play on internet/lstn to music mostly

Robert: me too! Sounds like we hav lots in common. Do u want 2 hav some fun with me? 
Sarah: wot sort of fun?

Robert: we could meet up in town this w/end

Sarah: to do wot?

Robert: just hang out. Do u hav a b frnd?

Sarah: no, but looking!

Robert: hav u ever kissed some1 b4?

Sarah: no, have thought bout it tho. Lol

Robert: cool! Lol. don't worry, I've kissed lots of people, u'll be safe with me. Hav u ever thought about more than kissing?

Sarah: not really. are you a perv?

Robert: not a perv, just like the sound of you, I think you're nice

Sarah: ok. Well maybe we could meet up

Robert: cool! lets meet up on sat then?

Sarah: ok, where?

Robert: outside museum, 2pm?

Sarah: ok, c u then

Robert: can’t wait

\section{Please read the following description of events as described by Sarah, the alleged victim.}

Sarah claims that two days later she met Robert in town as they had arranged in the chat room. According to Sarah, they got some lunch and walked around the shops for half an hour before Robert said he was bored and asked if she would like to go back to his place to listen to some music. Sarah says she agreed and they headed back to his house. She also claims that after 5 minutes, Robert sat down next to her and tried to kiss her but that she tried to pull away. Sarah then said Robert overpowered her and, holding her down, proceeded to have full penetrative sex with her. Sarah was very upset by this but claims was too distressed to tell anyone until a few days after the incident. 
Table 1: Factor Loadings, Eigenvalues \& Percentage of Variance Explained by Each Factor

\begin{tabular}{|c|c|c|c|c|c|c|c|c|}
\hline \multirow[b]{2}{*}{ Factors \& Items } & \multicolumn{8}{|c|}{ Factor Loadings } \\
\hline & 1 & 2 & 3 & 4 & 5 & 6 & 7 & 8 \\
\hline \multicolumn{9}{|l|}{ Factor 1: Perpetrator Culpability } \\
\hline \multicolumn{9}{|l|}{ Eigenvalue: $4.94:$} \\
\hline \multicolumn{9}{|l|}{ Variance: $11.0 \%$} \\
\hline Q09. perpetrator blame & .87 & & & & & & & \\
\hline Q10. perpetrator grooming & .87 & & & & & & & \\
\hline Q11. perpetrator manipulated & .75 & & & & & & & \\
\hline Q12. perpetrator responsibility & .64 & & & & & & & \\
\hline \multicolumn{9}{|l|}{ Factor 2: Victim Credibility } \\
\hline \multicolumn{9}{|l|}{ Eigenvalue: 3.07} \\
\hline \multicolumn{9}{|l|}{ Variance: $10.2 \%$} \\
\hline Q23. victim truthfulness & & .84 & & & & & & \\
\hline Q24. victim age truthfulness & & .77 & & & & & & \\
\hline Q25. victim age competence & & .71 & & & & & & \\
\hline Q26. victim age lie/naivety & & .57 & & & & & & \\
\hline
\end{tabular}

\section{Factor 3: Parent Culpability}

Eigenvalue: 2.62

Variance: $9.6 \%$

Q16. family blame $\quad .89$

Q17. family responsibility $\quad .82$

Q18. family guilt $\quad .66$

Q14. family prevention $\quad .61$

\section{Factor 4: Assault Severity}

Eigenvalue: 1.97

Variance: $9.6 \%$

Q21. assault severity $\quad .92$

Q22. police treatment $\quad .87$

Q20. victim trauma $\quad .70$

\section{Factor 5: Assault Unavoidable}

Eigenvalue: 1.68

Variance: $8.3 \%$

Q02. victim blame $\quad .81$

Q03. victim prevent $\quad .63$

Q06. victim sympathy $\quad .51$

\section{Factor 6: Victim Naivety}

Eigenvalue: 1.37

Variance: $7.0 \%$

Q04. victim trust

Q05. victim naivety

Factor 7: Victim Culpability

Eigenvalue: 1.24

Variance: $6.5 \%$

Q07. victim responsibility $\quad .75$

Q08. victim guilt $\quad .65$

\section{Factor 8: Uninterpretible $\dagger$}

Eigenvalue: 1.01

Variance: $4.7 \%$

Q15. family stop online chat $r .83$

Q13. perpetrator guilt $\quad-.49$

† Factor omitted from analysis. Note two other singlets were also omitted: highest loadings reported $\quad(\mathrm{n}=190)$ 
Table 2: Factor Ratings across Parental Interest, Victim Education, Victim Age \& Respondent Gender

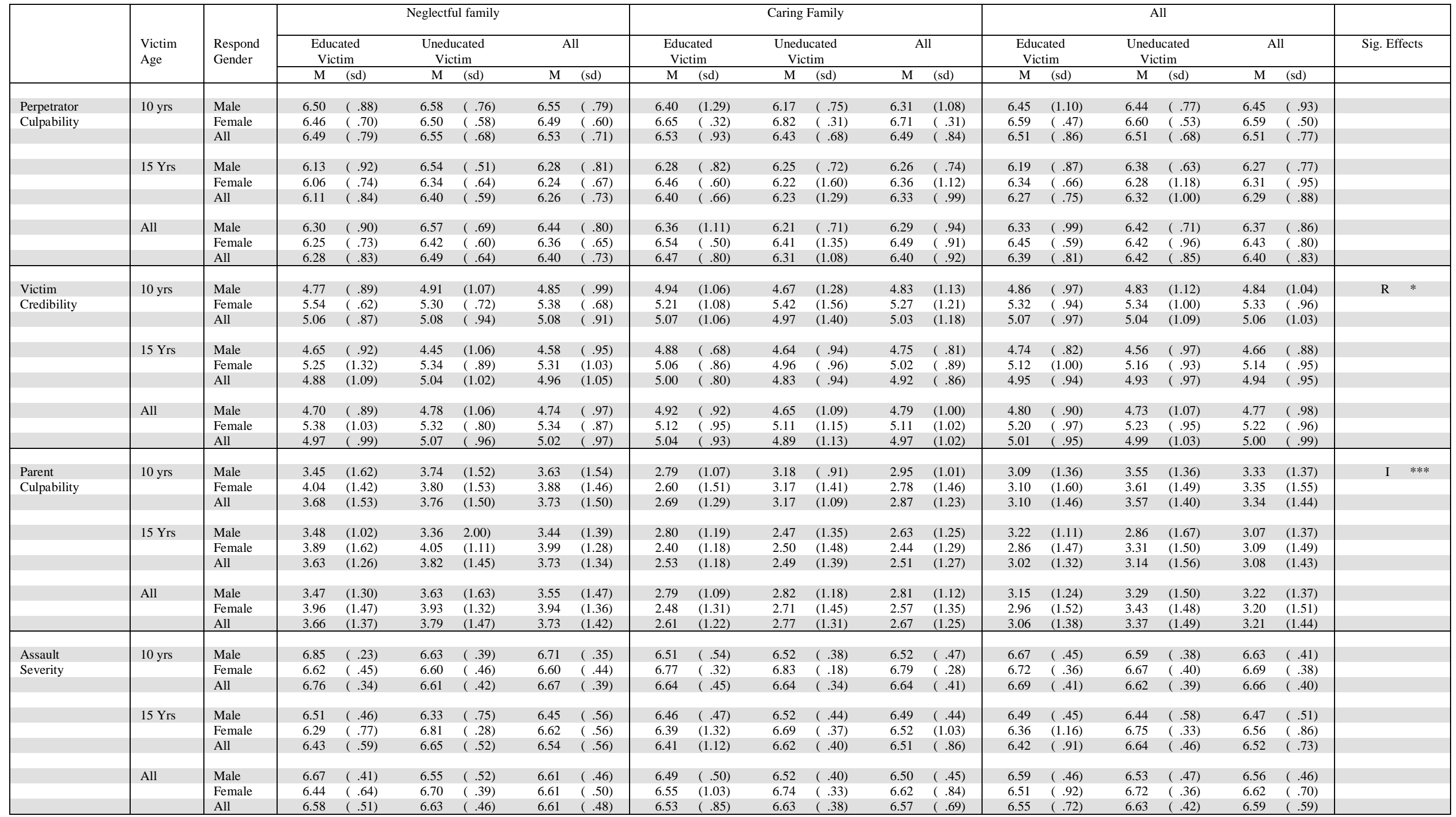

Range: 1 'not at all' to 7 'very / totally' with higher scores reflecting a more pro-victim/anti-perpetrator/ anti-family stance for all factors

Significant Parental Interest (I), Victim Education (E), Victim Age (A), Respondent Gender (G) and subsequent interaction effects found at the: * $p<.05$ ** $p<.01$ and $* * * p<.001$ levels (two-tailed) 
Table 2: Factor Ratings across Parental Interest, Victim Education, Victim Age \& Respondent Gender (continued)

\begin{tabular}{|c|c|c|c|c|c|c|c|c|c|c|c|c|c|c|c|c|c|c|c|c|c|}
\hline & \multirow{3}{*}{$\begin{array}{l}\text { Victim } \\
\text { Age }\end{array}$} & \multirow{3}{*}{$\begin{array}{l}\text { Respond } \\
\text { Gender }\end{array}$} & \multicolumn{6}{|c|}{ Neglectful family } & \multicolumn{6}{|c|}{ Caring Family } & \multicolumn{6}{|c|}{ All } & \multirow{3}{*}{ Sig. Effects } \\
\hline & & & \multicolumn{2}{|c|}{$\begin{array}{l}\text { Educated } \\
\text { Victim }\end{array}$} & \multicolumn{2}{|c|}{$\begin{array}{l}\text { Uneducated } \\
\text { Victim }\end{array}$} & \multicolumn{2}{|c|}{ All } & \multicolumn{2}{|c|}{$\begin{array}{l}\text { Educated } \\
\text { Victim }\end{array}$} & \multicolumn{2}{|c|}{$\begin{array}{l}\text { Uneducated } \\
\text { Victim }\end{array}$} & \multicolumn{2}{|c|}{ All } & \multicolumn{2}{|c|}{$\begin{array}{c}\text { Educated } \\
\text { Victim }\end{array}$} & \multicolumn{2}{|c|}{$\begin{array}{l}\text { Uneducated } \\
\text { Victim }\end{array}$} & \multicolumn{2}{|c|}{ All } & \\
\hline & & & $\mathrm{M}$ & (sd) & $\mathrm{M}$ & (sd) & $\mathrm{M}$ & (sd) & $\mathrm{M}$ & (sd) & $\mathrm{M}$ & (sd) & $\mathrm{M}$ & (sd) & $\mathrm{M}$ & (sd) & $\mathrm{M}$ & (sd) & $\mathrm{M}$ & (sd) & \\
\hline Assault & $10 \mathrm{yrs}$ & Male & 5.80 & $(.96)$ & 5.85 & (1.13) & 5.83 & (1.05) & 6.08 & $(1.06)$ & 6.11 & (1.26) & 6.09 & (1.12) & 5.95 & $(1.00)$ & 5.94 & (1.16) & 5.94 & $(1.08)$ & \\
\hline \multirow{7}{*}{$\begin{array}{l}\text { Assauit } \\
\text { Preventability }\end{array}$} & 10 yis & Female & 6.38 & $(.62)$ & 6.19 & $(.86)$ & 6.25 & ( .78$)$ & 6.33 & $\begin{array}{l}(1.43) \\
\text { (1.0) }\end{array}$ & 6.06 & $(.83)$ & 6.25 & (1.26) & 6.35 & (1.19) & 6.15 & $(.83)$ & 6.25 & $\begin{array}{l}(1.02) \\
(1.02)\end{array}$ & \\
\hline & & All & 6.03 & $(.87)$ & 6.00 & (1.02) & 6.01 & ( . .96$)$ & 6.21 & (1.24) & 6.09 & (1.07) & 6.16 & (1.17) & 6.13 & (1.10) & 6.03 & (1.03) & 6.08 & (1.06) & \\
\hline & 15 Yrs & Male & 5.67 & $(1.28)$ & 5.67 & $(1.31)$ & 5.67 & (1.25) & 5.54 & (.99) & 5.85 & (.94) & 5.71 & (.95) & 5.62 & (1.15) & 5.77 & $(1.08)$ & 5.68 & $(1.11)$ & \\
\hline & & Female & 5.15 & $(1.49)$ & 5.96 & (.79) & 5.67 & (1.14) & 6.09 & $(1.35)$ & 6.26 & $(.71)$ & 6.16 & (1.11) & 5.80 & (1.43) & 6.10 & $(.75)$ & 5.96 & (1.14) & \\
\hline & & All & 5.47 & $(1.35)$ & 5.87 & ( . .97) & 5.67 & (1.18) & 5.92 & (1.26) & 6.09 & (.82) & 6.00 & (1.07) & 5.72 & (1.30) & 5.98 & (.89) & 5.84 & (1.13) & \\
\hline & & Female & 5.72 & $(1.30)$ & 6.08 & $(.82)$ & 5.95 & (1.01) & 6.19 & $\begin{array}{l}(1.37) \\
(1.37)\end{array}$ & 6.19 & $(.73)$ & 6.19 & $\begin{array}{l}(1.16) \\
\text { (.0) }\end{array}$ & 6.04 & (1.35) & 6.12 & $(.78)$ & 6.08 & (1.09) & \\
\hline & & All & 5.73 & $(1.17)$ & 5.95 & (. .99) & 5.85 & (1.07) & 6.06 & (1.25) & 6.09 & (. .92) & 6.07 & (1.11) & 5.92 & (1.22) & 6.01 & (. .96) & 5.96 & (1.10) & \\
\hline \multirow{7}{*}{$\begin{array}{l}\text { Victim } \\
\text { Naivety }\end{array}$} & $10 \mathrm{yrs}$ & Male & 2.45 & $(1.23)$ & 2.00 & (1.31) & 2.17 & (1.28) & 2.27 & (1.07) & 1.94 & $(.88)$ & 2.14 & (.99) & 2.35 & (1.13) & 1.98 & $(1.16)$ & 2.16 & (1.15) & I $\quad *$ \\
\hline & & Female & $\begin{array}{l}2.45 \\
2.93\end{array}$ & $\begin{array}{l}(1.62) \\
(1.62)\end{array}$ & 2.43 & (1.54) & 2.60 & (1.55) & 2.00 & $(.84)$ & $\begin{array}{l}1.34 \\
1.50\end{array}$ & $\begin{array}{l}(.00) \\
(.45)\end{array}$ & $\begin{array}{l}2.14 \\
1.84\end{array}$ & $\begin{array}{l}(.56) \\
(.76)\end{array}$ & 2.33 & $\begin{array}{l}(1.1 .22) \\
\text { (1.5) }\end{array}$ & 2.15 & $\begin{array}{l}(1.10) \\
(1.37)\end{array}$ & 2.24 & (1.28) & IxAxR $\quad *$ \\
\hline & & All & 2.64 & (1.37) & 2.19 & (1.41) & 2.35 & (1.40) & 2.13 & (.95) & 1.77 & (.75) & 2.00 & (.89) & 2.34 & (1.16) & 2.05 & (1.24) & 2.19 & (1.20) & \\
\hline & 15 Yrs & Male & 2.08 & ( .98) & 2.71 & (1.68) & 2.30 & (1.26) & 1.69 & ( . .84) & 1.83 & (1.09) & 1.76 & (.95) & 1.93 & (.93) & 2.22 & (1.40) & 2.05 & (1.15) & \\
\hline & & Female & 1.81 & $(.70)$ & 2.07 & (1.34) & 1.98 & (1.14) & 2.14 & $\begin{array}{l}\text { (.94) } \\
\text { (.94) }\end{array}$ & 2.04 & (1.07) & 2.10 & (.98) & 2.04 & (.87) & 2.06 & (1.20) & 2.05 & (1.04) & \\
\hline & & All & 1.98 & (.87) & 2.29 & (1.45) & 2.13 & (1.19) & 2.00 & (. .92) & 1.95 & (1.06) & 1.98 & ( . .97$)$ & 1.99 & (.89) & 2.12 & (1.26) & 2.05 & (1.08) & \\
\hline & All & Male & 2.25 & (1.09) & 2.20 & (1.42) & 2.22 & (1.26) & 2.05 & (1.01) & 1.89 & (.96) & 1.97 & ( .98) & 2.16 & (1.05) & 2.07 & $(1.25)$ & 2.11 & (1.14) & \\
\hline \multirow{9}{*}{$\begin{array}{l}\text { Victim } \\
\text { Culpability }\end{array}$} & $10 \mathrm{yrs}$ & Male & 5.82 & (1.23) & 5.39 & (1.97) & 5.55 & (1.72) & 6.31 & (.93) & 5.50 & (1.85) & 5.98 & (1.40) & 6.08 & $(1.08)$ & 5.43 & $(1.90)$ & 5.74 & (1.59) & \\
\hline & & Female & $\begin{array}{l}3.02 \\
6.36\end{array}$ & (..56) & 6.36 & (1.01) & 6.36 & $(.87)$ & 6.27 & (1.01) & 6.33 & (..98) & 6.29 & $\begin{array}{l}(.498) \\
(.98)\end{array}$ & 6.30 & ( . (.86) & 6.35 & $(.97)$ & 6.33 & (.91) & \\
\hline & & All & 6.03 & (1.04) & 5.81 & (1.67) & 5.89 & (1.47) & 6.29 & $\begin{array}{l}(.05) \\
\text { (. }\end{array}$ & 5.83 & (1.58) & 6.12 & (1.22) & 6.18 & $\begin{array}{l}. .08) \\
(.98)\end{array}$ & 5.82 & (1.63) & 5.99 & (1.36) & \\
\hline & 15 Yrs & Male & 5.92 & $(1.34)$ & 5.36 & (2.12) & 5.73 & (1.62) & 5.44 & (1.35) & 5.94 & (1.10) & 5.71 & $(1.21)$ & 5.74 & (1.33) & 569 & (1.59) & 5.72 & (1.43) & \\
\hline & & Female & 5.44 & $(1.40)$ & 5.93 & (1.36) & 5.75 & (1.36) & 6.22 & (.99) & 5.92 & (1.58) & 6.10 & (1.25) & 5.98 & (1.16) & 5.93 & (1.44) & 5.95 & (1.30) & \\
\hline & & All & 5.74 & (1.35) & 5.74 & $\begin{array}{l}(1.62) \\
\text { (..6) }\end{array}$ & 5.74 & $\begin{array}{l}(1.47) \\
\text { (1.4) }\end{array}$ & 5.98 & (1.14) & 5.93 & $\begin{array}{l}(1.37) \\
\text { (1.5) }\end{array}$ & 5.96 & (1.24) & 5.87 & (1.23) & 5.84 & (1.48) & 5.86 & (1.35) & \\
\hline & All & Male & 5.88 & $(1.26)$ & 5.38 & (1.97) & 5.62 & (1.66) & 5.98 & (1.16) & 5.72 & (1.50) & 5.86 & (1.31) & 5.92 & $(1.20)$ & 5.52 & (1.78) & 5.73 & (1.51) & \\
\hline & & Female & 5.87 & $(1.16)$ & 6.14 & (1.19) & 6.05 & (1.17) & 6.24 & (. .98$)$ & 6.05 & (1.40) & 6.17 & (1.15) & 6.12 & (1.04) & 6.11 & $(1.27)$ & 6.11 & (1.16) & \\
\hline & & & 5.87 & (1.21) & $\begin{array}{l}0.14 \\
5.78\end{array}$ & (1.64) & 5.82 & (1.46) & 6.13 & (1.05) & 5.89 & (1.44) & 6.03 & (1.23) & 6.02 & (1.12) & 5.83 & (1.55) & 5.93 & (1.35) & \\
\hline
\end{tabular}

Range: 1 'not at all' to 7 'very / totally' with higher scores reflecting a more pro-victim/anti-perpetrator/ anti-parent stance for all factors

Significant Parental Interest (I), Victim Education (E), Victim Age (A), Respondent Gender (G) and subsequent interaction effects found at the: * $\mathrm{p}<.05$ ** $\mathrm{p}<.01$ and ${ }^{* * *} \mathrm{p}<.001$ levels (two-tailed) 